\title{
DEFI(CIÊNCIA) E BIOPOLÍTICA EDUCACIONAL: PRÁTICAS DE UMA EDUCAÇÃO CONTEMPORÂNEA
}

Bruno Leonardo Galdino de Azevedo, Ana Carolina Colnago Roco de Azevedo.

Universidade Estadual Paulista Júlio de Mesquita Filho - UNESP, Mestrando em Educação, Presidente Prudente - SP. Email: professorbrunoazevedo@gmail.com, carolcolnago@gmail.com

Bolsista pela Coordenação de Aperfeiçoamento de Pessoal de Nível Superior (CAPES).

\section{RESUMO}

Este trabalho é resultado de pesquisa desenvolvida ao longo do ano de 2018 no âmbito dos estudos relativos à Filosofia da Educação, tendo como objetivo abordar o tema da deficiência e suas implicações no cenário educacional, sendo orientada por trabalhos realizados por pesquisadores prestigiados no cenário nacional e que se aprofundaram na temática. Nomes como Pedro Pagni, Alfredo Veiga-Neto, Carlos Skliar, sensibilizaram os estudos na área da educação e ampliaram o debate sobre o sujeito deficiente, trazendo à baila valorosas discussões sobre o denominado devirdeficiente. A partir de pesquisa bibliográfica busca-se observar as denominadas práticas de governamentalidade e a deficiência como resistência as mesmas, por seu caráter acontecimental e enunciador da diferença em contramão à diversidade e os mecanismos inclusivos. Ao término da pesquisa, observa-se como a disseminação de práticas inclusivas e o aparato de governamento se propagaram nos discursos educacionais, criando enrijecimento enunciativo.

Palavras-chave: Governamentalidade, diferença, acontecimento, inclusão, deficiência.

\section{DEFI (SCIENCE) AND EDUCATIONAL BIOPOLITICS: PRACTICES OF A CONTEMPORARY EDUCATION}

\begin{abstract}
This work is a result of research developed during the year 2018 in the scope of studies related to Philosophy of Education, aiming to address the theme of disability and its implications in the educational scenario, being guided by works carried out by prestigious researchers in the national and that deepened in the thematic one. Names such as Pedro Pagni, Alfredo Veiga-Neto, Carlos Skliar, sensitized studies in the area of education and broadened the debate about the deficient subject, bringing to the table valuable discussions about the so-called becoming-deficient. From a bibliographical research it is sought to observe the so-called practices of governmentality and disability as resistance to them, due to its character of events and enunciator of difference against diversity and inclusive mechanisms. At the end of the research, it is observed how the dissemination of inclusive practices and the apparatus of governance propagated in the educational discourses, creating enunciative enunciative.
\end{abstract}

Keywords: Governmentality, difference, event, inclusion, disability. 


\section{INTRODUÇÃO}

O presente artigo busca adentrar o campo das deficiências, não com intuito de priorizar uma nuance, mas sim uma perspectiva mais geral, tendo como pressuposto a ideia em si do ser deficiente a partir de uma concepção educacional da denominada inclusão. Pensar a deficiência é estar diante daquilo que se qualifica enquanto déficit, uma falta correspondente a uma meta, amparada por toda uma lógica de normalização, onde o sujeito se torna refém de uma regra que qualifica e classifica. 0 mundo da deficiência passa a ser compreendido como estranho e surge a necessidade de torna-lo adequado. Podemos indagar que: "A normalização parece ser a linguagem do mundo atual, a identidade se constitui no princípio da lógica dos sujeitos que nele atuam e a ordem é o signo tão propagado de seu progresso" (PAGNI, 2015, p. 89).

Uma ordenação que se propaga em uma lógica de "governamentalidade" (FOUCAULT, 1992, p. 291), ou seja, essa arte de governar que extrapola o Estado, procurando criar estratégias que fortaleçam o controle sobre a vida, onde as práticas se tornam uma priorização de condutas. No espaço onde ocorrem as relações sociais, reproduz-se a lógica desse movimento enrijecido, já que a dinâmica te faz refém de uma forma que midiaticamente te informa. Assujeitar-se sob a égide do aparato inclusivo, que garante a sua liberdade em adequar-se à norma. Pensar o incluído como um fora que foi feito dentro, uma lógica de input e output, podendo ser nominado como processo de permuta ou escambo, em que se cria uma autonomia limitada, ordenada por todo um jogo, fissurado por essa "grelha" (FOUCAULT, 2010, p. 240b) que atravessa as relações de poder.

Diante de tais perspectivas, o chamado "devir-deficiente" (FREITAS, 2016, p. 253), aparece como "acontecimento" (DELEUZE, 2009, p. 152), acidentando perspectivas pré-normativas e descontruindo toda uma logicidade de padronização, numa vacância do devir que vem sempre ser preenchida pelo ser do agora, de uma deficiência insurgente e que abre espaços, sulcando o território formal e desdobrando-o, causando "inflexão" (DELEUZE, 1991, p. 33), fazendo com que a diferença seja a grande repetição e a singularidade o grande expoente diante das práticas de governamento. Observa-se que as relações seguem um fluxo que confrontam as modulações vigentes, criando uma rede de resistências ou escapes da grelha que a malha do poder sobrepõe.

\section{METODOLOGIA}

Através de uma metodologia qualitativa, busca-se, a partir de pesquisa bibliográfica, observar pontos de convergência entre os diferentes enunciados, já que:

[...] um enunciado é sempre um acontecimento que nem a língua nem o sentido podem esgotar inteiramente. Trata-se de um acontecimento estranho, por certo: inicialmente porque está ligado, de um lado, a um gesto de escrita ou à articulação de uma palavra, mas por outro, abre para si mesmo uma existência remanescente no campo da memória, ou na materialidade dos manuscritos, dos livros e de qualquer forma de registro; em seguida, porque é único como todo acontecimento, mas está aberto à repetição, à transformação, à reativação; finalmente, porque está ligado não apenas a situações que o provocam, e a consequências por ele ocasionadas, mas, ao mesmo tempo, e segundo uma modalidade inteiramente diferente, a enunciados que o precedem e o seguem (FOUCAULT, 2008, p. 31-32).

Objetiva-se adentrar o campo da "Biopolítica" (FOUCAULT, 2010b), com seus efeitos de poder sobre a inclusão, sendo que a perspectiva é da deficiência, que vem sendo uma das esferas mais violentadas pelas normativas inclusivas, criando possibilidades de novos debates. A abordagem a partir de publicações de autoridades no assunto e de periódicos em revistas com alta qualificação, buscam respaldar a importância da questão e como tem se espraiado a temática nos últimos anos. 


\section{RESULTADOS}

Tendo como pressuposto o levantamento bibliográfico realizado, pode-se inferir algumas possibilidades acerca do tema da deficiência na área educacional:

A alteridade deficiente é um exemplo da voracidade com que o mundo moderno, sem soluções, inventa e exclui a esses outros. O lugar no mundo dos outros deficientes tem sido permanentemente relacionado e confundido com seu lugar institucional, e seu lugar institucional foi freqüentemente profanado pela perversidade de pensá-lo todo nos termos estreitos de inclusão/exclusão (SKLIAR, 1999, p. 16).

Assim, corroboramos a necessidade em explorar a potencialidade da deficiência que é negada dentro do discurso normativo, fazendo com que cada vez mais o sujeito qualificado de deficiente possa não ser categorizado de maneira excludente. A busca pelo aperfeiçoamento perante uma educação empreendedora, faz com que a sociedade se torne um campo de competição em que regras são estabelecidas para que se adquira status de vencedor, relegando os classificados como não aptos, a se tornarem párias em um sistema seletivo. Através da ideia de tornar o próprio sujeito um "capital humano" (FOUCAULT, 2010b, p. 289) sob a tutela dos chamados investimentos educativos, facultando-o a uma gama de apreensões que farão dele apto a atender as demandas do mercado, compondo um quadro de uma paisagem capitalista.

O deficiente é esse a ser enquadrado:

Foucault e Bauman compreendem a Modernidade como o tempo em que a ordem deixou de ser vista como algo natural, como "algo que estava aí", e passou a ser entendida simplesmente enquanto ordem e, como tal, um problema a ser resolvido, uma disposição que, por não estar desde sempre aí, deve ser imposta ao mundo natural e social (VEIGA-NETO, 2001, p. 26).

Pelo jogo das relações de saber e poder, cria-se uma segmentação de superfícies enunciativas, que vão moldando o indivíduo, suprimindo subjetividades e produzindo um discurso diário, onde deve-se passar por ele para se tornar adequado. Assim:

[...] a inclusão e a exclusão acontecem no âmbito da norma; e, na medida em que esta é tida como natural, aquelas operações de ordenação - aproximação, comparação e classificação e atendimento das especificidades - parecem naturalmente necessárias. Deriva de tal naturalização a própria justificativa epistemológica e ética do ordenamento. Em resumo, a norma acaba funcionando como uma matriz de inteligibilidade na qual as políticas e as práticas de inclusão fazem sentido e são justificadas (VEIGA-NETO; LOPES, 2007, p. 959).

Desse prisma que a inclusão será apresentada na educação brasileira e será ampliada em políticas públicas que buscam mecanismos de controle para dar conta da nova demanda, já que os indivíduos "anormais" (FOUCAULT, 2010c) não estão mais escondidos ou eliminados dos extratos sociais, emergem pela busca de igualdade de direitos com a proliferação de suas singularidades e a garantia da diversidade, embora a diferença jamais seja abrigada pelo diverso.

\section{DISCUSSÃO}

Pensar a deficiência é estar diante de grandes desafios que se apresentam em toda uma forma de se estruturar a sociedade, fazendo com que o tema se torne cada vez mais presente nos debates de ordem pública e privada. Abrir o espaço ao deficiente, deixar que o mesmo se torne visível em um mundo que o ignorava é algo significativo e não pode mais ser negado, gerando consequências que repercutem pelas esferas sociais:

[...] a desconfiança parece ser gerada justamente pelo temor, pelo desconforto ou pelo incomodo de que essa potência deficiente, por assim dizer, poderia se converter em ato e transformar os modos de existência, produzindo uma intensidade da vida e um movimento 
num lugar em que somente existiria o seu controle técnico-racional e uma suposta sensação de segurança gerada pela fixidez, pela identidade e pela normalização dos demais sujeitos.. (PAGNI, 2016, p. 357)

A deficiência representa essa experiência limite de não se adequar, de apresentar-se como uma resistência à norma, fazendo com que sua condição seja a da transgressão e provocando nos outros envolvidos, os qualificados como "normais", a também questionarem a sua condição na sociedade e sobre os posicionamentos diante das relações de poder. Uma revolução propriamente dita, já que repercute pela trama social, política, econômica e cultural, causando questionamentos quanto ao "investimento educativo" (FOUCAULT, 2010b, p. 289), já que a ideia de capital humano estaria ameaçada por aquilo que foge ao adequado e às necessidades de atender demandas de mercado:

Chegamos assim à noção de que o salário é nada mais do que a remuneração, o rendimento afectado a um certo capital, capital este que se chama capital humano na medida em que, precisamente, a competência-máquina da qual é o rendimento não pode ser dissociada do indivíduo humano que é o seu portador (Ibid., p. 287).

Quando se institui que existe um portador, mas que sua condição de portar está associada a uma deficiência, isso desvalorizaria os indivíduos, tornando-os estigmatizados, criando subgrupos, pessoas de segunda classe. Eis que surge a inclusão como a grande redentora, utilizando um aparato para remediar, procurando adequar e tornar os sujeitos mais próximos do padrão exigido, possibilitando meios de ter acesso, buscando formas de equalizar, utilizando falsos subterfúgios para promover uma ilusão de paridade. Desta feita:

[...] relega-se a diferença ao esquecimento, à errância, ao obliterado lugar do inominável. A palavra de ordem é: a diferença deve ser trabalhada, escrutinizada, controlada nas atividades e no tempo; enfim, deve-se normalizá-la, pois só assim a diferença teria lugar na sociedade dos vivos (LOPES, 2016, p. 304).

Existe todo um cálculo que faz com que os mecanismos de governamento penetrem nas camadas da deficiência através do aparato inclusivo. O indivíduo incluído passa a fazer parte do sistema com sua perspectiva de interesse, que busque se padronizar e adequando-se, adquira a noção de aceitação, que seu diferencial seja exposto como significativo de sua singularidade, contribuindo com a potencialidade angariada para a produtividade da sociedade, além de ter uma jurisprudência que lhe garante igualdade de direitos, tornando-o um cidadão comum, apesar de suas idiossincrasias:

Com o sujeito de interesse tal como os economistas o fazem funcionar, temos então uma mecânica totalmente diferente da dialéctica do sujeito de direito, porque é uma mecânica egoísta, é uma mecânica imediatamente multiplicadora, é uma mecânica sem qualquer transcendência e é uma mecânica em que a vontade de cada um se vai conciliar espontaneamente e como que involuntariamente com a vontade e os interesses dos outros (Foucault, 2010b, p. 342).

O desejo de pertencimento faz com que a mecânica funcione, ditando o rito através do ponto comum chamado interesse, fazendo com que se multipliquem os desejos em relação ao fazer parte de, em uma lógica de atendo imediatista que tem por função garantir o mínimo de satisfação, para que a inconformidade seja o grande motor, aquilo que move cada um para o sonho possível. Mas é justamente das possibilidades que se deve supor que: "A liberdade nunca é mais - mas já é muito - do que uma relação actual entre governantes e governados, uma relação em que a medida da 
«demasiado pouca» liberdade que existe é dada pelo «ainda mais» de liberdade reivindicada" (Ibid., p. 93).

Discutindo sobre os limites do governamento e suas práticas sobre a deficiência, acaba-se esbarrando em novas formas de liberdade que eclodem nessa rede, fazendo com que novos espaços sejam explorados, com perspectivas que se renovam. O próprio Foucault já havia enxergado que o poder ocasiona resistências, o que faz com que a pesquisa apresentada corrobore essa lógica, já que existe sempre um preço a se pagar, seja pela perda de liberdades que a violência dos mecanismos provoca ou justamente as novas liberdades que irão surgir a partir dos confrontos, tornando-os imprescindíveis nas práticas de política. Resta saber sobre até que ponto pode-se provocar essa liberdade no ser deficiente:

Entre as questões que desafiam aqueles que se relacionam forçosa ou deliberadamente com esse outro, chamado de deficiente, por um lado, é o de ver na experiência singular que essa relação proporciona a emergência de uma diferença radical e de um acontecimento que problematiza a sua própria existência e faz dessa deficiência alheia um devir da transformação de si mesmo; por outro lado, para esses com quem se relacionam, o desafio parece o de se esse sujeito chamado deficiente pode ou não, como qualquer um, pelas limitações genéticas, biológicas ou acidentais que a ele se impõe, se não se emancipar desse estado, ao menos exprimir a diferenciação ética em que vive, entre as tantas outras que se apresentam na esfera pública. (PAGNI, 2017, p. 271)

\section{CONSIDERAÇÕES FINAIS}

Por meio das análises feitas nessa pesquisa, procura-se problematizar o tema da deficiência sob a perspectiva educacional, já que tem sido alvo de inúmeras práticas, que vão desde interesses governamentais - expostos por iniciativas de políticas públicas - até o intenso debate feito por profissionais da área da educação, vitimados tanto pela falta de formação sobre o tema, quanto pela não iniciativa que se faz presente nas escolas, onde ainda predominam práticas arcaicas e que promovem a exclusão.

O discurso inclusivo muitas vezes aparece apenas como um dever a ser cumprido, faltando a sensibilização no que se refere aos afetos, buscando estar mais próximo do outro. 0 deficiente é o que rompe os tabus e cria laços, trazendo para o espaço escolar - que se encontra tão violentado - , novas formas de interagir, perceber a diferença e lidar com o acontecimento do agora, daquilo que faz parte das relações humanas, que é justamente o ter contato e a percepção de alteridade.

Cabe também questionar como as normas são impostas e o aparato de governar a vida, a chamada biopolítica, pode ser percebida nos mecanismos que cada vez mais procuram dar conta da realidade social e calcular formas de controle sobre a população, criando uma produtividade que atende um mercado que tem sido contrário a tudo que o conceito de vida engloba, criando assim a grande contradição que Foucault já havia exposto, o discurso da vida atrelado ao controle sobre o deixar morrer.

Assim, devemos pensar a deficiência como uma eficiência de resistência e procurar compreender cada vez mais, essa condição humana que foge do racionalismo monopolista, resgatando o mistério que existe no imprevisível e não mais condicionando pessoas a uma razão governamental, mas buscando um "cuidado de si e dos outros" (FOUCAULT, 2010a, p. 169), numa ética do cuidar, do poder fazer e agir para que aconteça, somando as potencialidades, admitindo a impotência, criando modos de sobrevivência. 


\section{REFERÊNCIAS}

DELEUZE, Gilles. A Dobra: Leibniz e o barroco. Trad. Luiz B. L. Orlandi. Campinas, SP: Papirus, 1991.

DELEUZE, Gilles. Lógica do Sentido. Trad. Luiz Roberto Salinas Fortes. 5a Ed. São Paulo: Perspectiva, 2009. (Estudos ; 35 / dirigida por J. Guinsburg)

FOUCAULT, Michel. A Arqueologia do Saber. Trad. Luiz Felipe Baeta Neves. 7a Ed. Rio de Janeiro: Forense Universitária, 2008.

FOUCAULT, Michel. A Hermenêutica do Sujeito: curso dado no Collège de France (1981-1982). Edição estabelecida sob a direção de Francois Ewald e Alessandro Fontana, por Frédéric Gros; Trad. Márcio Alves da Fonseca, Salma annus Muchail. 3a Ed. São Paulo: Editora WMF Martins Fontes, 2010a. (Obras de Michel Foucault)

FOUCAULT, Michel. Microfísica do Poder. Org. e Trad. Roberto Machado. 10 $\underline{a}$ Ed. Rio de Janeiro: Edições Graal, 1992.

FOUCAULT, Michel. Nascimento da Biopolítica. Trad. Pedro Elói Duarte. Lisboa, Portugal: Edições 70, 2010b.

FOUCAULT, Michel. Os Anormais: curso no Cóllege de France (1974-1975). Trad. Eduardo Brandão. São Paulo: Editora WMF, 2010c. (Coleção Obras de Michel Foucault)

FREITAS, Alexandre Simão. O devir-deficiente da pedagogia: notas para uma antropologia filosóficoeducaional da plasticidade. Childhood \& Philosophy. Rio de Janeiro, v. 12, n. 24, mai.-ago. 2016, p. 231-260.

LOPES, Rodrigo Barbosa. Esboço para um pensamento da diferença e do devir deficiente na educação. Childhood \& Philosophy. Rio de Janeiro, v. 12, n. 24, mai.-ago. 2016, p. 277-308.

PAGNI, Pedro. A emergência do discurso da inlusão escolar na biopolítica: uma problematização em busca de um olhar mais radical. Revista Brasileira de Educação. Marília, SP, v. 22, n. 68, jan.-mar. 2017, p. 255-272.

PAGNI, Pedro. Diferença, subjetivação e educação: um olhar outro sobre a inclusão escolar. Proposições. Porto Alegre, RS, v. 26, n. 1, jan.-abr. 2015, p. 87-103.

PAGNI, Pedro. Ética da amizade e deficiência: outras formas de convívio com o devir deficiente na escola. Childhood \& Philosophy. Rio de Janeiro, v. 12, n. 24, mai.-ago. 2016, p. 343-370.

SKLIAR, Carlos. A invenção e a exclusão da alteridade "deficiente" a partir dos significados da normalidade. Educação e Realidade. Porto Alegre, RS, v. 24, n. 2, jul.-dez. 1999, p. 15-32.

VEIGA-NETO, Alfredo. Incluir para saber. Saber para excluir. Pro-posições. Porto Alegre, RS, v. 12, n. 2 3, jul.-nov. 2001, p. 22-31. 
VEIGA-NETO, Alfredo; LOPES, Maura Corcini. Incluir para saber. Saber para excluir. Educ. Soc. Campinas, SP, v. 28, n. 100 - Especial, out. 2007, p. 947-963. 